\title{
Education for the Good Society: the integrity of academic practice
}

\author{
JON NIXON \\ School of Education, University of Sheffield, UK
}

\begin{abstract}
This paper argues that universities need to reclaim a public and inclusive language for education that reflects the moral ends and purposes of academic practice. It claims that there are certain moral goods implicit in the activities - of research, scholarship and teaching - that comprise such practice; and it defines these goods in terms of virtuous dispositions towards truthfulness, respect and authenticity. The moral conditions of academic reconstruction necessarily include a commitment by academic practitioners to the development, in themselves and others, to these goods of learning.
\end{abstract}

\section{Introduction}

The university . . . is a kind of utopian state . . . It's a grandiose idea, because most of us tend to think of the university as a place where one has a career, which is certainly true, and there's nothing wrong with that; but if you wanted to you could have a somehow more extended idea of what the university is ... something of this sort is at least useful to get discussion started. And it can be done by individuals. (Said, 2004, p. 190)

This paper is written as a kind of 'open letter' to colleagues working in higher education: hence the somewhat repetitive use of the first person plural. Of course, this 'we' is an imagined community of occupational groups that are increasingly atomised through the fractionalisation and stratification of the institutional contexts within which their members work. This rhetorical device is not intended to iron out these differences and inequalities, but to highlight the need for academic workers to develop what Taylor (2004) has termed a 'social imaginary': 'that common understanding that makes possible common practices and a widely shared sense of legitimacy' (p. 23). The resources necessary for developing and consolidating such an imaginary, I argue towards the end of this piece, include certain dispositions that are intrinsic to academic practice: dispositions towards truthfulness, respect and authenticity. It is these virtues that provide academic practice-across its constituent activities of research, scholarship and teaching-with its moral integrity. 


\section{Reclaiming a Public Language for Education}

In recent years universities in particular and the non-profit-making sector in general, has become increasingly dominated by a language which fails to recognise the rich unpredictability of learning: a language of cost-efficiency, value for money, productivity, effectiveness, outcome-delivery, target-setting and auditing. We are increasingly encouraged, as scholars, teachers and researchers, to think in business terms. Indeed, it is difficult to think outside this terminology, given its all-pervasive dominance. On occasion, we have little option other than to speak its language in order to fulfil the requirements of the internal and external accountability and funding mechanisms that ensure our survival.

We ought not to be sanctimonious about this. We have all, as intellectual workers, in varying degrees had to learn to be bi-lingual: to utter the standard platitudes of managerialism, while adopting within our own street culture of academic journals and collegial dialogue an older demotic. We cannot afford to ignore the language of managerialism, but nor can we afford to ignore its deep ideological drift. The language of inputs and outputs, of clients and products, of delivery and measurement, of providers and users, is not just a different way of talking about the same thing. It radically alters what we are talking about. It constitutes a new way of thinking about teaching and learning. Ultimately, it affects how we teach and how we learn. It has designs upon us and upon what we understand by educational studies.

What universities can do-must do-is forge a public language which has the capacity to affirm and construct an educated citizenry. The dominant language currently at our disposal is emphatically not directed towards such ends and purposes. For all its insistence on 'user relevance', it is an exclusive language of technocrats and bureaucrats, the ideological purpose of which is to endorse technocratic and bureaucratic ways of thinking about education. Against these ways of thinking universities must seek to open up the debate regarding the ends and purposes of education, to expand and render more inclusive its civic spaces and to recognise the diversity of human presence that comprises those spaces. That is the prime task of any university seeking to reclaim its civic leadership: to reclaim, that is, a public and inclusive language for higher education.

The second task is to provide an inclusive forum for deliberative debate within the public domain. 'The academy is ... not', as Said (2004, p. 181) puts it, 'a place to resolve sociopolitical tensions ... but it is a place to understand them, to understand them in their origin, to understand them in the way in which they are going, in which what is brought to bear is intellectual process'. By that I take Said to mean that the academy should not seek to be dispassionate, but it should insist upon its disinterestedness: it exists, in other word, to provide a civic space within which vested interests are acknowledged and called to account. Government and privately sponsored think tanks for all their bright ideas cannot perform this function. I am not suggesting that such bodies perform no useful function. A good case could be made out for the various quasi-non-government organisations that dominate the policy making scene having made a valuable, if limited, contribution to the debate on higher education. But that contribution carries with it no obligation to critically scrutinise the interests they and their sponsors have invested in the knowledge they produce and propagate.

Of course, the university sector has its own interests, some of which are admittedly selfserving. Universities have, after all, to survive in an increasingly market-led policy context. But they have one defining interest which is institutionally unique: an interest, that is, in the intrinsic goods of learning and in the critical examination of particular programmes and agendas of change in the light of a relentless examination of those goods. The purpose of 
any university is not only to bring society back to the questions it needs to ask of itself but to insist that those questions are formulated and addressed, as MacIntyre (1990, p. 22) puts it, 'in the best rationally defensible way'.

\section{Management, Money and Marketing!}

... the three horsemen of the new apocalypse-management, money and marketing. (Eyre, 2003)

The new public management of education was driven by the resurgence of neo-liberal market ideologies that dominated the last quarter of the last century and continue to exert an influence on the way in which universities are managed. It was based on the assumption of a general breakdown of trust in the public and non-profit making sectors and on the further assumption that public trust is best regained through systems of accountability that support competition across these sectors. If only the public and non-profit making sectors could learn from and behave as if they were a part of the private sector all would be well! From that forlorn hope unravelled the endless palaver of performativity - target setting, league tables, inspection regimes - that now characterises the university sector and dominate the working lives of those located within that sector.

As O’Neill (2002) pointed out in her BBC Reith Lectures, this widely endorsed mode of institutional management is itself part of the problem, not part of the solution. Far from reinstating public trust in public institutions, it has encouraged what she calls a 'culture of suspicion' which is then used to justify the centralised control of those institutions:

In theory the new culture of accountability and audit makes professionals and institutions more accountable to the public. This is supposedly done by publishing targets and levels of attainment in league tables, and by establishing complaint procedures by which members of the public can seek redress for any professional or institutional failures. But underlying this ostensible aim of accountability to the public the real requirements are for accountability to regulators, to departments of government, to funders, to legal standards. The new forms of accountability impose forms of central control — quite often indeed a range of different and mutually inconsistent forms of central control. (2002, pp. 52-53, italics in original)

This statement constitutes a serious indictment of the new public management of higher education. The charge against that management regime is its lack of both transparency and internal consistency. It fails, according to O'Neill, to declare its underlying purposes and to render those purposes coherent in organisational practice. It is a fudge: a muddle masquerading as a serious response to a problem it fails to address let alone analyse.

Far from encouraging institutions within the public and non-profit making sectors to engage with their publics, the new public management of higher education has served to render them defensive and inward looking: 'we are heading towards defensive medicine, defensive teaching and defensive policing' (p. 50). The moral trajectory of professional practice towards public service through the exercise of professional judgement brought to bear on highly complex, indeterminate problems has been deflected. Both the professionals and their publics are thereby the poorer. The accountability regimes which characterise the new public management of education have scored an embarrassing 'own goal'. In a bureaucratic effort to open up institutions, they have managed to close them in culturally. 
The increasing reliance on mechanisms of accountability and audit in the management of universities is complemented by the increasing reliance of universities, and indeed other institutions within the public and non-profit-making sectors, on commercial funding. Shumar (1997) refers to this same process in terms of 'the commodification of higher education'; Slaughter and Leslie (1997) see it culminating in what they call 'the entrepreneurial university'; while Aronowitz (2000) labels what he calls 'the corporate university' as 'the knowledge factory'. Each of these writers provides different explanations for the rapid acceleration of the process of commercialisation, but they broadly agree on what is at stake: namely, that the academic practices associated with the university have "come to be valued in terms of their ability to be translated into cash or merchandise and not in other ways, such as aesthetic or recreational pleasure. Eventually the idea that there are other kinds of value are lost' (Shumar, 1997, p. 5). That loss of all values other than the values of the marketplace further erodes public trust in the universities by restricting the notion of public concern to the narrow self-interests of the commercial sector.

Bok (2003) analyses this process of commercialisation from the perspective of a seasoned senior academic, and respected legal scholar, within American higher education. Pointing to the 'rapid growth of money-making opportunities provided by a more technologically sophisticated, knowledge-based economy' (p. 15), Bok cites as an example the fact that, in the USA, 'corporations doubled and redoubled their share of total academic research support, increasing it from $2.3 \%$ in the early 1970 s to almost $8 \%$ by the year 2000 ' (p. 12). 'Within a few short decades', he maintains, 'a brave new world had emerged filled with attractive possibilities for turning specialised knowledge into money’ (pp. 13-14). Williams (1995, p. 177) points to a similar trend within the UK. 'The transformation has been dramatic', he argues: 'within ten years, students have been metamorphosed from apprentices to customers, and their teachers from master craftsmen to merchants'.

The future to which such a process is likely to lead is, argues Bok (2003), a bleak one:

One can imagine a university of the future tenuring professors because they bring in large amounts of patent royalties and industrial funding; paying high salaries to recruit 'celebrity' scholars who can attract favourable media coverage; admitting less than fully qualified students in return for handsome parental gifts; soliciting corporate advertising to underwrite popular executive programs; promoting Internet courses of inferior quality while cancelling worthy conventional offerings because they cannot cover their costs; encouraging professors to spend more time delivering routine research services to attract corporate clients, while providing a variety of symposia and 'academic' conferences planned by marketing experts in their development offices to lure potential donors to the campus. (2003, pp. 200-201)

At issue are the underlying purposes of professional practice and the capacity of professionals to reach out to a wide and diverse public. The choice, as Reid (1996) puts it, is between 'higher education or education for hire'. The complex societal forces operating in the late-modern age require a radical reappraisal of those purposes and a radical redefinition of what we understand by the increasingly differentiated and stratified public sphere. However, the ways in which we have set about that reappraisal and that redefinition, through the mechanisms of new public management and a collapse into wholesale commercialism, presage an ideological dead-end. The endemic problem of the redistribution of power across new force-fields of difference cannot be resolved through piecemeal 
measures that seek to reconcile centralised control with an over-reliance on unmediated market forces. As Bok (2003, p. 208) concludes, 'universities will find it difficult to rebuild the public's trust ... In exchange for ephemeral gains in the continuing struggle for progress and prestige, they will have sacrificed essential values that are all but impossible to restore'.

A consequence of this Faustian exchange of 'ephemeral gains' for 'essential values' is, among other things, the low morale among academic workers: the sense of being undervalued and of having no effective input into the way in which universities are run or the direction in which they are heading. However, if loss of values is part of the problem, then the sense academics have of their own professional identity must be part of the solution. Any serious attempt at institutional change necessarily involves a commitment to professional reconstruction. Without that commitment, institutional change (and, indeed, broader policy change) lacks all substance.

\section{The Moral Conditions of Academic Reconstruction [1]}

Universities, as we academic workers are constantly reminded, undoubtedly contribute to wealth creation and the economic regeneration of the regions within which they are located. They provide skills and understandings, without which an advanced society could not hope to compete within the global market. They are key partners in economic regeneration schemes that benefit regions and help locate those regions within a broader frame of economic competition. They are part of the complex infrastructure of global capitalism, which relies increasingly on the recognition of knowledge transfer as a key component of economic well being. Their trade is knowledge and they have undoubtedly become increasingly successful in this entrepreneurial endeavour. Some universities, at least, have grown up and got wise to the economic reality of late capitalism; and the more grown up and wised up they have become, the greater their competitive edge.

Economic growth, however, is not the prime purpose of the university. Universities exist to hold the mirror up to society and, in so doing, ask it to examine its assumptions and its underlying logic. It must be emphasised that this is not necessarily an either/or. Sometimes, happily, the university and society can have it both ways. But when 'the chips are down', as Arendt put it, hard decisions have to be taken. Then the question of what universities are for resurfaces and has to be addressed. Sometimes, in the interests of learning, universities have to take a stand against what is seen to constitute progress or growth (as when, for example, the imposition of managerialist structures threatens the very practice of learning). Because of this possible eventuality, universities have to sustain their underlying purposefulness as a resource for an indeterminate future. The university must be a repository of these other, sometimes oppositional, ways of thinking about why we do what we do.

The university is above all a civic space: a space where people come together with the purpose of learning together, with a respect for the practices that sustain such learning, and with a sense of there being dispositions that have to be achieved in order for learning to take place. This claim can, however, no longer be taken for granted. Like all claims regarding the purpose of the university it is increasingly contested and has to struggle for recognition within a policy context that is fraught with competing priorities and agendas. To insist upon the primacy of that claim is not to deny the complexity of the context within which academic workers forge their moral careers and seek to define for themselves a new academic professionalism. It is merely to insist that, in positioning itself within that context, the university needs to affirm as a condition of its survival the centrality of learning as a civic necessity. 
Williams (2002) reminded us, in the last book of his published during his lifetime, of the importance to the continuation of learning of the notion of truthfulness. In that sense a university might be seen as an extension of a good home-a space within which we learn to tell the truth within these 'domestic' parameters. To claim that the university is a 'civic' space is to assume that the university exists to search for ways of speaking the truth within a wider forum. The possibility of learning and of their being a civic space within which we can, in difference, learn together is itself a condition of hope. The university is a space within which that condition can be realised. It is not the only space, but it remains a significant space to which those of us who acknowledge the authority of truthfulness may, and indeed do, return in troubled times.

Truthfulness relies upon a commitment to accuracy in respect of belief and sincerity in respect of professing those beliefs that we hold to be accurate. Learning how to learn is in large part a matter of acquiring those dispositions that make such a commitment possible. Truthfulness does not presuppose an ultimate truth; it aspires towards a set of practices that limit the potential violence of untruth. Truthful people may sometimes deceive, tell lies; but they acknowledge the troubling and disabling impact of their deceptions and lies both on their own lives and on the well-being of others. To seek to be accurate in respect of the beliefs one holds and sincere with regard to the professing of those beliefs is intrinsic to becoming a good academic practitioner. In that sense we might say that accuracy and sincerity are the virtuous dispositions associated with truthfulness.

Learning presupposes, in its emphasis on truthfulness, respect for the other. Sennett (2003) reminds us that respect necessarily takes as its starting point a deep attentiveness to difference. That attentiveness involves identification through sympathy and empathy, but must move beyond those sentiments to an honesty regarding the difficulty of practising respect within a deeply unequal world. We cannot collapse the self into the other. The civic space provided by the university allows us to grow into respect through a process of painful standing back - through deliberation, argumentation and an acknowledgement of the deep disagreements which may, ultimately, be the only common ground we share.

There is, Sennett (2003) goes on to argue, a kind of phasing into respect through identification and then through recognition. What might then emerge is respectful distance: the respect accorded to those we know to be different, but have learnt are part of whatever (Arendt's phrase again) 'care for the world' might mean. What respect does is weld our recognition of difference and our commitment to a more socially just society into a kind of morally functional disunity - an openness to difference, while trying to work through the quite specific and always culturally-specific social justice project. Living life purposefully for the betterment of an imagined good society, which is precisely what the university exists for, is a matter of entertaining that disunity - that openness - and privileging it against the symbolic violence of premature foreclosure. The virtuous dispositions of accuracy and honesty implicit in the traditions of teaching, learning and humanistic scholarship are crucial means by which, as academic practitioners, we set about that task.

Learning presupposes, finally, the possibility, and indeed as Taylor (1991) would have it, the necessity of authenticity. It provides the potential for living life in such a way that truthfulness and respect become what we are in our relations with one another. Authenticity is the public face of truthfulness and respect and involves the additional virtuous dispositions of courage and compassion. Judged by the strictest standards of authenticity none of us can claim to be a moral success. Insofar as some of us do we risk the eventual accusation of hypocrisy. But we may rightly think of authenticity as a kind of journey; and, in so far 
as we do so, the university is one of the institutions through which we may choose our long march. It is not the only institutional route any of us will take, but it is an important one and one which we must keep open for others.

Authenticity, I repeat, is not an end-point. In a tangled world of interrelated privacies it may even seem a chimera. But it is a notion to which the university must hold fast. The idea is that life can be lived all of a piece for ourselves and others; that truthfulness can become a way of life for ourselves and others; and that respect can become part of that life for ourselves and others. It is a near impossibility, but not quite an impossibility. We must begin, at precise points and within specific sectors, the task of recreating from an increasingly alienated workforce the possibility of a new academic professionalism. It is, I am arguing, only from within our own academic practice that we can discover the virtuous dispositions of courage and compassion to set about that task.

\section{Conclusion}

Research, scholarship and teaching share a necessary relationship based upon the virtuous dispositions implicit in academic practice. The increasing tendency to distinguish institutions of higher education in terms of either their research capacity or their teaching capacity certainly reproduces deep inequalities within the system. It also, however, fractures the moral coherence of the academic practice comprising those activities. Research, scholarship and teaching do not simply hang together instrumentally. They are dependent upon and at the same time help sustain a moral framework, the pivotal points of which are truthfulness (accuracy/sincerity), respect (attentiveness/honesty), and authenticity (courage/compassion). The university, viewed as a 'utopian state' (which is precisely how Said suggests we should view it), is a civic space within which these particular virtues, and the dispositions associated with them, are allowed to flourish.

Although research, scholarship and teaching are clearly very different kinds of activity, each requires a dispositional orientation towards these virtues. That moral orientation is a defining feature of the field of academic practice within which these various activities are located. As activities each is clearly very different and involves a differing range of skills and understandings. However, as moral endeavours, these activities have much in common; and what they have in common is, in part at least, a sense of moral purposefulness in respect of the virtues of truthfulness, respect and authenticity. Those involved in these different activities share what Pring (2003, p. 64) has called 'the deep down feeling concerning how they ought to act'.

It is important to insist upon the moral coherence of academic practice precisely because of the increasing stratification of the higher education sector, whereby deep divisions of labour are being systematically engineered and then justified on the spurious grounds of consumer choice. Within this context the notion of 'widening participation' becomes meaningless, since what students will be participating in at different points within the system will not just be different (in the naively benign sense of that term) but will differ qualitatively. The reclamation of the moral bases of academic practice, by us as academic practitioners, is essential if universities are to contribute to the building of the good society. 'It can', as Said insists, 'be done by individuals' (2004, p. 190): by people like ourselves who, through our academic practice, are continuing to learn how to be accurate and sincere, attentive and honest, courageous and compassionate. 


\section{J. Nixon}

\section{Notes}

[1] This section presents a much abbreviated form of an argument elaborated in the central chapters of my forthcoming book Universities and the Good Society: the moral bases of academic professionalism (Nixon, 2005).

\section{References}

ARonowitz, S. (2000) The Knowledge Factory: dismantling the corporate university and creating the higher learning, Boston, MA, Beacon Press.

BoK, D. (2003) Universities in the Market Place: the commercialisation of higher education, Princeton, Princeton University Press.

Eyre, R. (2003) The BBC is one of the few things in Britain that works, The Guardian, 27 September, 22.

MacIntyre, A. (1990) Three Rival Versions of Moral Enquiry: encyclopaedia, genealogy and tradition, London, Duckworth.

NixOn, J. (forthcoming) Universities and the Good Society: the moral bases of academic professionalism, London, RoutledgeFalmer.

O’Neill, O. (2002) A Question of Trust, Cambridge, Cambridge University Press.

Pring, R. (2003) The virtues and vices of an educational researcher. In P. Sikes, J. Nixon \& W. CARR (eds) The Moral Foundations of Educational Research: knowledge, inquiry and values, Maidenhead, Open University Press \& McGraw-Hill Education.

ReID, I. (1996) Higher Education or Education for Hire? Language and Values in Australian Universities, Rockhampton, Central Queensland University Press.

SAID, E. (2004) Power, Politics and Culture: interviews with Edward W. Said, London, Bloomsbury.

Sennett, R. (2003) Respect: the formation of character in an age of inequality, London, Allen Lane.

Shumar, W. (1997) College for Sale: a critique of the commodification of higher education, London, The Falmer Press.

Slaughter, S. \& LesLie, L.L. (1997) Academic Capitalism: politics, policies and the entrepreneurial university, Baltimore and London, John Hopkins University Press.

TAYLOR, C. (2004) Modern Social Imaginaries, Durham, Duke University Press.

TAYLOR, C. (1991) The Ethics of Authenticity, Cambridge, MA, Harvard University Press.

Wildiams, B. (2002) Truth and Truthfulness: an essay in genealogy, Princeton, Princeton University Press.

Williams, G.L. (1995) The 'marketisation' of higher education: reforms and potentials in higher education finance. In D.D. Dill \& B. Sporn (eds) Emerging Patterns of Social Demand and University Reform: through a glass darkly, Oxford, New York \& Tokyo, Pergamon Press \& The International Association of Universities Press. 